\title{
The role of asymmetry: Evidence from Chinese Treasury bond market*
}

\author{
DiJUn TAN $^{\dagger}$ AND YiXIANG TIAN
}

Volatility asymmetry widely exists in the stock and exchange market, but little evidence has been provided in the bond market, especially the Treasury bond market with fewer impacts related to private information. This paper provides an empirical study on the volatility asymmetry in the Chinese Treasury bond market (CTBM). The question what we are mostly interested is the role of asymmetry in volatility modeling in the Treasury bond market, including econometric testing of asymmetry and analyzing of its effect on volatility forecasting. Quite different from previous results in the stock or exchange market, by estimating varied volatility models, empirical results in this paper show that volatility asymmetry is insignificant in CTBM, but it also provides important and indispensable information for volatility forecasting. Due to the special pricing way of Treasury bonds as well as low liquidity in CTBM as a result of non-actively trading, the fact that information-based impacts in CTBM are not as common as that in the stock or exchange market may contribute to these results.

Keywords AND PHRAses: Asymmetry, Chinese Treasury bond market, High frequency data, Realized volatility, Volatility forecasting.

JEL CLASSIFICATION: G12, G14, G32.

\section{INTRODUCTION}

Does volatility asymmetry that positive and negative innovations have different effect on future volatility exist in every market? In the stock market, firm-specific, industryspecific information come to the market or assets frequently, so the answer may be yes. In the exchange market, information from their own currency countries, or other related countries, or the dominant currency countries (such as US) may also come to the market or currencies frequently, so the answer may be yes too. However, in the bond market, especially the Treasury bond market, the situation is different. For nearly no default risk, the future cash flow for the Treasury bonds is fixed, so their valuation is only varied with the discount rate, which is mostly affected by the change

* For insightful suggestions and comments, we appreciate the two anonymous referees and the Co-Editor, as well as Zeng Yong, Li Ping in UESTC. Any error is my own responsibility.

$\dagger$ Corresponding author. of monetary policies or other related macro-variables, such as CPI (Consumer Price Index), the supply of currency and so on. However, these variables or policies are rather stable and not varied sharply or frequently, particular in the daily time level. So, comparing with the stock or exchange market, there is much less private information or fewer informationbased impacts that would affect the valuation of Treasury bonds in a short time interval. With these special facts, whether volatility asymmetry also exists or not in the Treasury bond market need to be tested.

Actually, volatility asymmetry has been found existing widely and playing important role for risk management in stock and exchange market. Typically, Engle (2004) shows that volatility asymmetry is important for the estimation of Value at Risk (VaR). For a portfolio of S\&P500 stocks, ignoring the asymmetry in volatility may lead to a significant underestimation of VaR. Andersen et al. (2003), Theorem 2, find that if return-volatility asymmetry is important and the forecast horizon is relatively long, say monthly or quarterly, then one may expect the empirical return distribution to display asymmetries that are incompatible with symmetric return distributions. By using of realized volatility, their empirical results show asymmetric response of major exchange rates to economic announcements in the U.S. With high-frequency data and realized volatility, Wang and Yang (2006) also examine the volatility asymmetry in bilateral foreign exchange rates and trade weighted indices (TWI), and find evidence of asymmetry in daily realized volatility of AUD, GBP, and JPY against USD. Moreover, their results show that asymmetry may persist over periods of several years, and the asymmetry is in different directions for different currencies: volatility of AUD and GBP increases when they depreciate against USD, but volatility of JPY increases following JPY appreciation against USD.

In this paper, we test the volatility asymmetry in the Chinese Treasury bond market (CTBM hereafter) with high frequency data and realized volatility of the Treasury index in the Shanghai Security Exchange market. It is interesting to study the volatility asymmetry in this market for many reasons. First of all, most of the previous studies related to volatility asymmetry only focus on stock or exchange market, but little attention has been paid to the Treasury market. For the special way of price discovering of Treasury bonds, previous results in the stock or exchange market need to be further tested in the Treasury bond market. 
Secondly, China has the largest fast growing economy in the world. The size of its economy stands at $\$ 2.7$ trillion in 2006, ranked after US, Japan and Germany. CTBM that is closely related to Chinese economy and gradually viewed as a good place for international investment is valuable to be studied. This is helpful for the risk management of these investors who are now in, or plan to come to, this market.

Thirdly, comparing with the Chinese stock market or Treasury market in US or Euro-area countries, CTBM develops more slowly and has smaller size and number of bonds. Moreover, in China, there is no fixed time and specified term for the issuing of Treasury bond, which is usually serviced only for the irregularly demand of macroeconomic control, such as increasing the government payment, the adjustment of the currency demand or supply, and so on. The price discovering and the stylized facts of volatility for this market have rarely been tested, especially with the high-frequency data and realized volatility.

Compared with previous studies related to volatility asymmetry, this paper also employs diversified volatility models. Four types of volatility models are applied in this paper. The first type refers to the ARCH-family models. Since the seminal paper of Engle (1982), the advance of ARCH-family models such as GARCH (Bollerslev (1986)), GARCH-M (Engle (1987)) etc. give us more capability to model volatility in the financial markets. Moreover, to capture the popular dynamics of volatility asymmetry, models such as TARCH (Zakoian (1994)), EGARCH (Nelson (1991)) are also applied widely in practice.

The second type of model applied in this paper is the ARMA model based on realized volatility. In recent years, a new way of volatility modeling based on high frequency data was proposed by Andersen, Bollerslev, Diebold, Labys (ABDL hereafter, Andersen and Bollerslev (1997), Andersen et al. (1999)) named realized volatility (RV). ABDL have shown that by sampling intra-day returns sufficiently frequently, the realized volatility can be arbitrarily close to the underlying integrated volatility, which is a natural volatility measure. Based on high frequency data, realized volatility provides a benchmark to evaluate other volatility models (Andersen et al. (2003)). What's more, traditional time series models, ARMA for example, can be estimated on realized volatility series directly to explore the volatility stylized facts, such as the volatility asymmetry. The analysis related to the Chinese capital market with high frequency data is just the matter of recent years with the availability of data. The Treasury bond index in Shanghai Security Exchange (SHSE) market was created since Feb.2003, and from then on the intra-day data of the index are available. This paper examines the role of volatility asymmetry with realized volatility and ARMA model structure, in which realized volatility is computed firstly, and then the ARMA type models are estimated on realized volatility series.

The third model refers to the heterogeneous autoregressive (HAR) volatility model proposed by Corsi (2003). The basic idea of HAR model is that there are many types of investors in the market, for which each has its regular trading time interval. It is usually assumed that there are three types of investors with daily (short term), weekly (medium term) and monthly (long term) trading interval. Corsi (2003) finds that HAR model provides superior performance in volatility forecasting. To include asymmetry in HAR, this paper proposes a modified HAR to capture the different effect of positive and negative innovations on future volatility.

The fourth type of model, proposed this paper, is a volatility model that combines with both the realized volatility and GARCH structure. GARCH volatility and realized volatility are two different ways of volatility modeling, and can not be replaced each other. ${ }^{1}$ Then, intuitionally, the question is that whether the two models or methods can work together to use both the good structure of $\mathrm{ARCH}$ model and the affluent information of inter-day data, or whether realized volatility is helpful to modeling and forecasting conditional volatility. This paper introduces realized volatility to conditional volatility model, and a RV-GARCH model is constructed. Our work is also built on the former work of Blair et al. (2001), Hol and Koopman (2002). A RV-EGARCH model that combines with RV and EGARCH model is also introduced in this paper to capture asymmetric dynamics.

With these models, this paper focuses on two issues related to the volatility asymmetry in CTBM. The first issue is to test the volatility asymmetry with these econometric models and compare the results with other markets, and the second one is to discuss the role of asymmetry in volatility forecasting. In addition, to enforce our empirical results, Monte Carlo simulations are provided. The empirical results and simulations show that the asymmetric relation between return and volatility in CTBM is insignificant. However, asymmetric specifications provide important and indispensable information to volatility forecasting. As a result of the special pricing way of Treasury bonds, as well as of the special background of the Chinese capital market, the information-based impacts in the Chinese Treasury

\footnotetext{
${ }^{1}$ Some reasons are responsible for the individuality of the two types of models. First of all, GARCH model is employed for time series with regularly sampled data and it is rarely used to un-regularly sampled data directly. Secondly, the market open and close system will affect the volatility modeling for intra-day data with GARCH structure. Thirdly, the inter-day periodicity of volatility will affect volatility modeling with GARCH structure. Moreover, it is uncertain whether realized volatility can be used to measure the conditional heteroskedasticity. According to the work of Andersen et al. (2000), and Forsberg and Bollerslev (2002), return standardized by realized volatility is nearly normal, $f\left(r_{t} \mid R V_{t}\right) \sim N\left(0, R V_{t}\right)$, but the distribution of $f\left(r_{t} \mid R V_{t-1}\right)$ is not certain. So, the ex-post realized volatility $R V_{t}$ should be modeled further to get the ante-realized volatility or conditional volatility $f\left(r_{t} \mid R V_{t-1}, \ldots, R V_{1}\right)$ as the estimator of the conditional heteroskedasticity. Here, another question arises. Can a model be better than ARCH to capture the volatility clustering or other stylized facts in financial market? The answer is uncertain. At least, it is difficult now.
} 
bond market are not as common as that in the stock, or exchange market. Some hypotheses about the source of volatility asymmetry, leverage effect or feedback effect, that emphasize the role of private information in pricing discovering may not come to existence in the Treasury bond market. Results in this paper indicate that it's different for the role of volatility asymmetry between (Treasury) bond and stock or exchange market. However, the asymmetry effect of impacts related to the discount rate may be also important and helpful to volatility forecasting. In fact, the accuracy of volatility forecasting around big news is the key factor for a successful volatility model though these events are not so common in the market. So, when considering the volatility symmetry, the models generally capture more dynamics, though subtle, and behave better in volatility forecasting.

The rest of the paper is organized as follows. Section 2 introduces the theory of realized volatility. Then, the best sampling frequency is selected to estimate realized volatility of the Chinese Treasury bond market in section 3. In section 4, empirical models based on RV are applied to test the volatility asymmetry in CGTM. In section 5, various volatility models are introduced and their asymmetric counterparts are constructed to test the role of asymmetry in volatility forecasting. Some Monte Carlo simulation results are provided in section 6 . Last section concludes.

\section{INTRODUCTION OF REALIZED VOLATILITY}

\subsection{Integrated volatility}

Though the ARCH volatility or implied volatility models are applied widely in practice, the most natural approach is integrated volatility (Andersen et al. (2000)). Letting $W$ be a standard Wiener process and $p_{k}$ denote the arbitrage-free logarithmic price process (Andersen et al. (2001)), then $p_{k}$ can be written as,

$$
d p_{k}=u_{k} d t+\sigma d W
$$

or,

$p_{k}(t)-p_{k}(t-1) \equiv r_{k}(t)=\int_{t-1}^{t} u_{k}(s) d s+\int_{t-1}^{t} \sigma_{k}(s) d W(s)$

Now, the standard calculations of quadratic variation, which is unbiased estimator of variance in theory, yield,

$$
\operatorname{Qvark}(t)=\left[p_{k}, p_{k}\right]_{t}-\left[p_{k}, p_{k}\right]_{t-1}=\int_{t-1}^{t} \sigma^{2}(s) d s
$$

Here, the right part of the above equation, $\int_{t-1}^{t} \sigma^{2}(s) d s$, is the so-called integrated volatility.

\subsection{Realized volatility}

Let $P_{t, i}$ denote the $i^{t h}$ intra-day price of the security at day $t$. With sampling frequency $\Delta t$, we can get the intraday returns,

$R_{t, \Delta t, i}=\ln P_{t, i \Delta t}-\ln P_{t,(i-1) \Delta t}, t=1, \ldots, T, i=1, \ldots, N_{\Delta t}$

So the daily return is,

$$
R_{t}=\ln P_{t, N_{\Delta t}}-\ln P_{t-1, N_{\Delta t}}, \quad t=1, \ldots, T
$$

Now the realized volatility $v\left(t_{i}\right)$ at time $t_{i}$ is defined as (Dacorogna et al. (2001)),

$$
v\left(t_{i}\right)=\left[\frac{1}{N_{\Delta t}} \sum_{i=1}^{N_{\Delta t}}\left|R_{t, \Delta t, i}\right|^{p}\right]^{\frac{1}{p}}
$$

The exponent $p$ is often set to 2 so that $v\left(t_{i}\right)^{2}$ is the unbiased estimator of the return variance. When $p=1$, the volatility $v\left(t_{i}\right)$ is just the fine volatility (Muler et al. (1997)). $v\left(t_{i}\right)$ is the volatility for time interval $\Delta t$, but the popular used one is the scaled form (Dacorogna et al. (2001)), such as the one-day-volatility or one-year-volatility, which can be transformed as,

$$
v_{\text {scaled }}=\sqrt{\frac{\Delta t_{\text {scale }}}{\Delta t}} \cdot v\left(t_{i}\right)
$$

Here, $\Delta t_{\text {scale }}$ is the scaled term (time), one month or one year etc.

\subsection{Sampling frequency of realized volatility modeling}

The fact that realized volatility is the consistent estimator of integrated volatility is appealing, but, unfortunately, the assumption that log asset prices evolve as a diffusion process becomes less realistic when the time interval reduces (Corsi et al. (2001)). To compute the realized volatility, the sampling frequency $\Delta t$ should be selected firstly. On one hand, higher frequency can reduce the statistical errors. On the other hand, the microstructure effect rising from bid-ask bounce will make the volatility estimator be biased (Andersen and Bollerslev (1997), Andersen et al. (2000)). To select the best sampling frequency, Andersen and Bollerslev (1997) proposed a statistic as,

$$
V R=\frac{N_{\Delta t} \cdot \operatorname{Var}\left(R_{t, \Delta t, i}\right)}{\operatorname{Var}\left(\sum_{i=1}^{N_{\Delta t}} R_{t, \Delta t, i}\right)}
$$


If $\Delta t$ is the best sampling frequency, the volatility with frequency $\Delta t$ should yield the scaling law. So, the optimal $\Delta t$ will produce a $V R$ close to one. ${ }^{2}$

\section{REALIZED VOLATILITY OF CTBM}

\subsection{The daily realized volatility of CTBM}

The bond index in Shanghai Security Exchange (SHSE) market is used in this paper to examine the role of asymmetry in the Chinese Treasury bond market (CTBM). Treasury bonds in China were issued first time in 1981. There was no primary and secondary market, or little liquidity, before 1987. From 1987 to 1996, Over-the-counter (OTC) trading was allowed. After 1997, the inter-bank bond market is created; from then on the market size and trading volume increases greatly. Now, both short and long term bonds, invertible and un-invertible bonds, fixed and flexible yield bonds exist in CTBM. Moreover, the Treasury bond index of Shanghai stock exchange market has been created after Feb. 24, 2003, which is helpful to examine the market volatility.

Tick-by-tick data of Chinese Treasury bond index from Jun.1 2004 to Dec.31 2005 is employed in this paper. The data is supported by CSMAR Corporation, one of the chief data supporters in China. There are 391 transaction days with total observations of 634489 ticks, about average 1622 ticks per day. ${ }^{3}$ Because there is no short-sell system in CTBM, no trade may means bad news (Diamond and Verrecchia, 1987), so the linear interpolation scheme (Daconogna et al, 2001) is selected, and the 1-minute logarithm returns are shown in figure 1.

It has been found that the $V R$ statistic is almost close to one (0.9974) with sampling frequency of 15 minutes, so 15 -min is selected as the optimal $\Delta t$ to calculate the realized volatility. The daily realized volatility of CTBM computed with equal to 15 minutes is shown in figure 2 . The maximal daily volatility ${ }^{4}$ is 0.0061 about 0.0061 , and the minimum one $2.135 \times 10^{-4}$.

\footnotetext{
${ }^{2}$ There are two general ways of realized volatility modeling. The first one is to choose the best sampling frequency on the tick-by-tick data, typical works including ABDL $(1997,1999,2003)$ etc. The second one is to get the realized volatility directly from the tick-by-tick data but take some adjustment of noise, typical works including Corsi et al. (2001), Zhang et al. (2005) etc. For the microstructure effect rising from bidask bounce may make the volatility estimator be biased, both of the two methods use some skills to reduce this effect, but with different ideas. The first one, as what we have done in this paper, the best sampling frequency is selected at which the bias is marginal, and for the second one, the autocorrelations rising from the microstructure effect is adjusted with some special algorithms. In this paper, we adopt the first one and believe that it may not qualitatively affect the results on the role of asymmetry, because the results in this paper, as shown later, is so robust that the results stands out in every case of the four types of models.

${ }^{3}$ As the developing of electronic trading system of Shanghai stock market, more than 16000 ticks of trading can be processed each second, with which the tick-by-tick index data is produced. More information is included in the official website of Shanghai stock market:
}

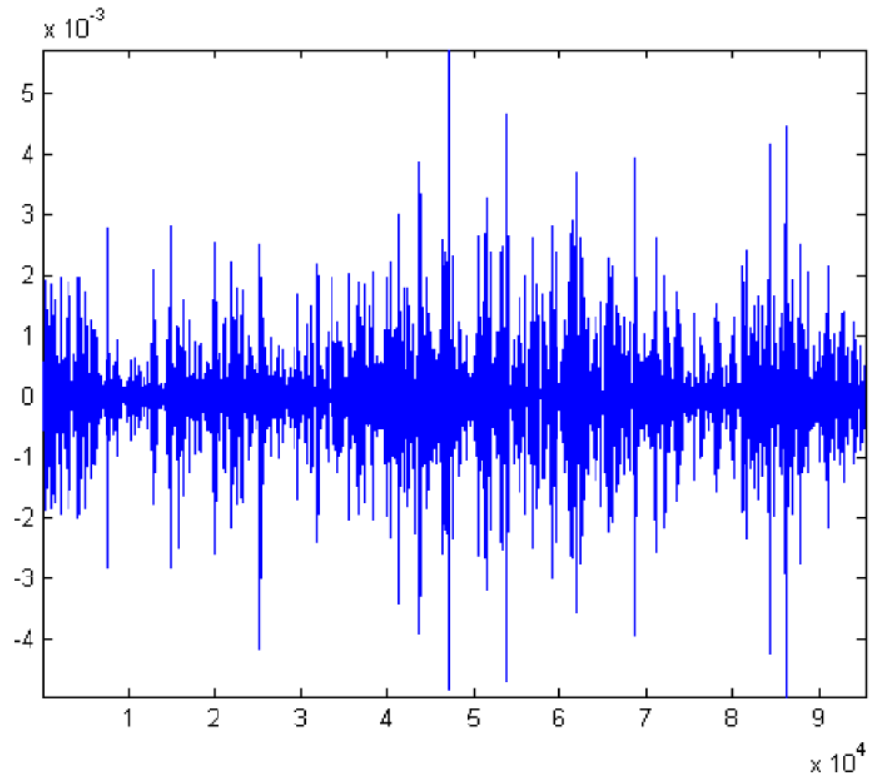

One-minute intra-day returns for the Chinese Treasury bond index are shown here, including 391 days from Jun.1 2004 to Dec.31 2005. The returns are the logarithms of the one-minute bond indices, which come from the linear interpolation (Daconogna et al., 2001) on the 634489 ticks of the intra-day high-frequency index data in the sample period.

Figure 1. One-minute returns on the Chinese Treasury bond index.

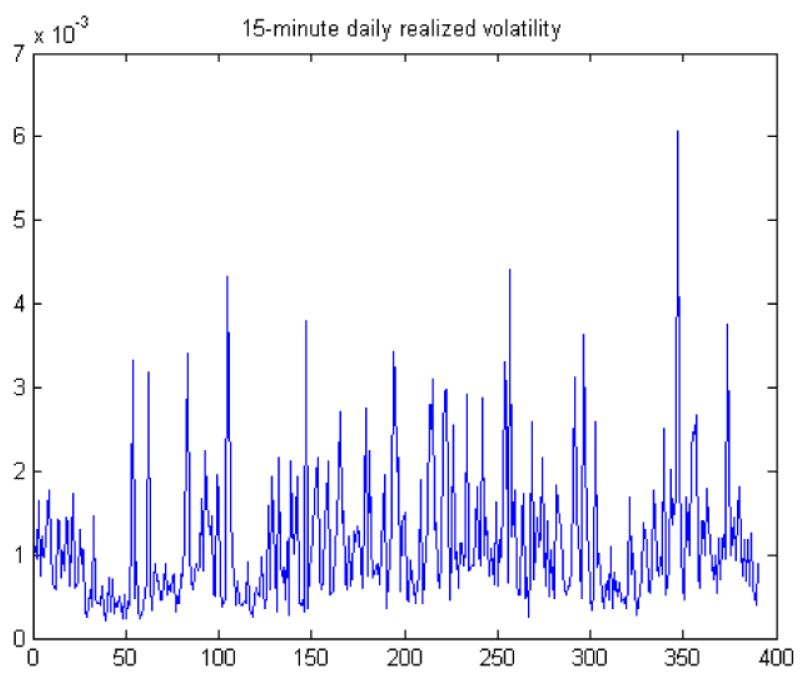

The daily realized volatility is shown here, for which 15-min is selected as the optimal according to the statistics of Andersen et al. (1997). The daily realized volatility of CTBM is computed with equal to 15 minutes.

Figure 2. Daily volatility of CTBM index with 15-min sample.

http://www.sse.com.cn/sseportal/ps/zhs/sjs/jysjs.shtml

${ }^{4}$ In the following sections of this paper, without special explanation, "daily volatility" denotes the daily realized volatility computed at sampling frequency of 15 minutes. 


\subsection{The unconditional and conditional distribution of the return}

As mentioned above, if the return series are decomposed as $R_{t}=\sigma_{t} \varepsilon_{t}$, where, $\varepsilon_{t} \sim$ iid $N(0,1)$, and $\sigma_{t}$ is the conditional standard deviation at time $t$, then the $\sigma$-standardized return is,

$$
\varepsilon_{t}=\frac{R_{t}}{\sigma_{t}}
$$

Here, $\varepsilon_{t}$ is so-called conditional or standardized return series. $\sigma_{t}$ is unknown and can be estimated by various of volatility models.

A relative consistent result, in empirical studies, about the unconditional distribution of return series is that daily return is not normally distributed, and increasing the length of the sampling frequency, to weekly, fortnightly, or monthly, will reduce the variance persistence and kurtosis of the returns (Baillie and Bollerslev (1989)). For intraday returns, Andersen et al. (2000) find that the unconditional distributions of exchange rate returns are symmetric but highly leptokurtic, and realized volatility can capture the chief facts of exchange rate volatility better than GARCH models. With respect to CTBM, the distribution of unconditional returns and standardized returns is shown in Table 1.

It can be found that the unconditional distribution of CTBM return series is absolutely different from normal distribution. The conditional distributions of returns standardized by GARCH, EGARCH and TGARCH also have kurtosis higher than three. The Jaque-Bera statistics and the pvalues demonstrate that these conditional distributions are not normal distributions either. However, the conditional distribution of returns standardized by realized volatility is nearly normal, as shown in the last column of Table 1 . The $\mathrm{p}$-value of the hypothesis that the conditional distribution of CTBM return standardized by realized volatility is normal can not be rejected even at $10 \%$ significance levels. This indicates that realized volatility is much better to describe the
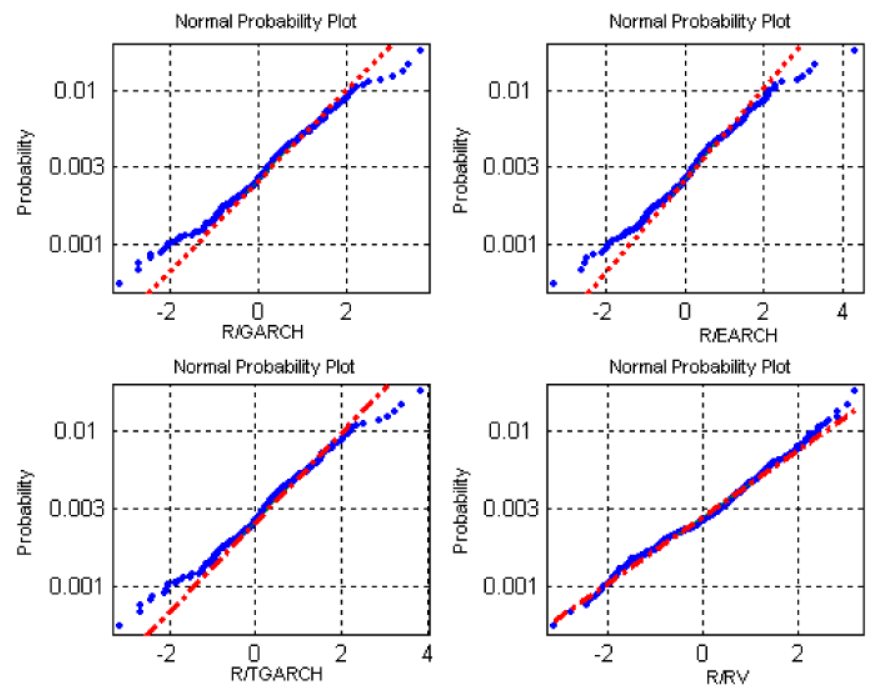

Q-Q plots for the four standardized return series are shown here. The red dotted line connects the 25th and 75th percentiles of the data. The blue dotted lines describe the percentiles of the sample. If the series conform to normal distribution, the blue line will appear linear, superposed over the red one; otherwise, it may follow a curve.

Figure 3. QQ-graph of conditional distribution of returns.

variation of the return than other volatility models. These results are reinforced by the Q-Q plots of the standardized return series shown in Figure 3.

In figure 3 , the red dotted line connects the 25 th and 75 th percentiles of the data. The blue dotted lines describe the percentiles of the sample. If the series conform to normal distribution, the blue line will appear linear, superposed over the red line; otherwise, it may follow a curve. The conditional distribution of return standardized by realized volatility is more linear than other ones. That is, realized volatility capture the volatility dynamics of CTBM better than the

Table 1. The unconditional and conditional distribution statistics of daily return

\begin{tabular}{lccccr}
\hline Statistics & Unconditional & $R_{t} / G A R C H\left(\sigma_{t}\right)$ & $R_{t} / E G A R C H\left(\sigma_{t}\right)$ & $R_{t} / T G A R C H\left(\sigma_{t}\right)$ & $R_{t} / R V_{t}$ \\
\hline Mean & 0.0003 & 0.2362 & 0.2453 & 0.2427 & 0.2653 \\
Median & 0.0003 & 0.2191 & 0.2114 & 0.2185 & 0.4005 \\
Maximum & 0.0057 & 3.6982 & 4.3167 & 3.8498 & 3.1987 \\
Minimum & -0.0051 & -3.1662 & -3.3289 & -3.1583 & -3.1104 \\
Std.Dev & 0.0013 & 1.0013 & 1.0027 & 1.0025 & 1.1448 \\
Skewness & -0.1764 & -0.0385 & 0.0547 & 0.0120 & -0.2101 \\
Kurtosis & 4.8332 & 3.9269 & 4.0985 & 3.9105 & 2.6967 \\
Jaque-Bera & 56.7800 & 14.0953 & 19.8525 & 13.5161 & 4.3739 \\
Probability & 0.0000 & 0.0009 & 0.0000 & 0.0012 & 0.1123 \\
\hline
\end{tabular}

The descriptive statistics for the distribution of unconditional returns and standardized returns are shown in Table 1. If hypotheses that return series are decomposed as $R_{t}=\sigma_{t} \varepsilon_{t}$, where, $\varepsilon_{t} \sim$ iid $N(0,1)$, and $\sigma_{t}$ is the conditional standard deviation at time $t$, then $\varepsilon_{t}=R_{t} / \sigma_{t}$ is standardized return series and may conform to normal distribution; Here, GARCH $\left(\sigma_{t}\right), E G A R C H\left(\sigma_{t}\right)$ and $T G A R C H\left(\sigma_{t}\right)$ are respectively the conditional volatility of GARCH, EGARCH and TGARCH model, and $R V_{t}$ is the realized volatility. 
GARCH, TGARCH or EGARCH model. These results are consistent with that of Andersen et al. (2000) who discuss the foreign exchange market.

\section{ECONOMETRIC TEST OF VOLATILITY ASYMMETRY}

Asymmetry refers to that negative returns have stronger effect on future volatility than positive ones. With realized volatility, the relationship between return and volatility (RV and logarithm RV) of CGBM is shown in figure 4.

The upper two graphs of figure 4 describe the relation between return and volatility or logarithm volatility for two
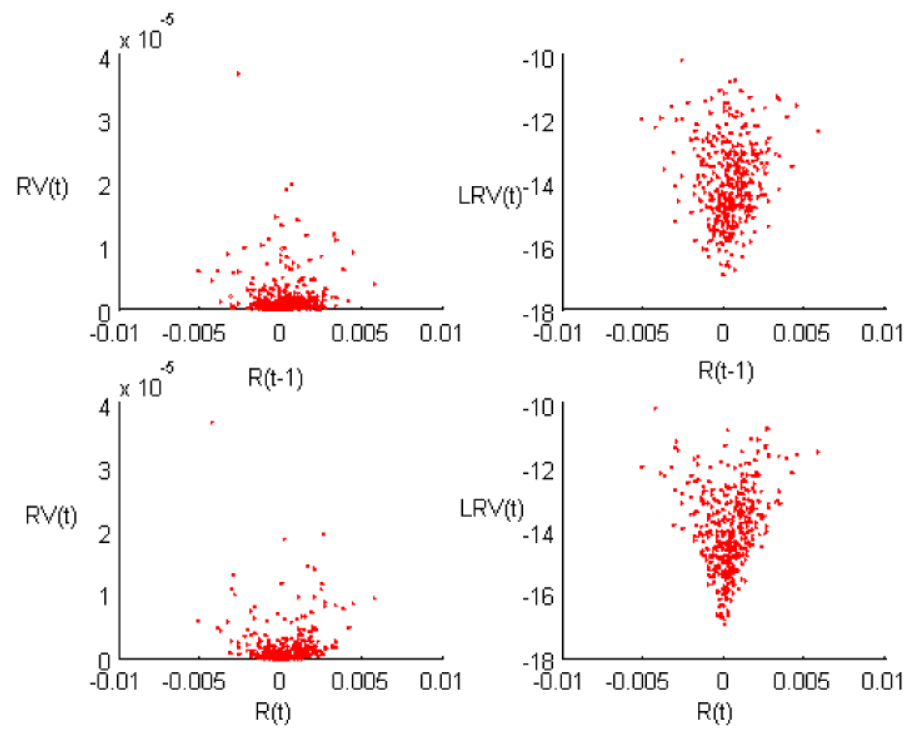

The relationship between return and realized volatility or logarithm of realized volatility is shown here. The upper two graphs in the figure describe the relationship in two successive days, and the lower two graphs describe the relationship at the same day.

Figure 4. "V"-shape relationship between return and volatility. successive days, and the lower two graphs describe the relationship at the same day. It can be found that volatility and return exhibit a "V"-shape pattern for all the four situations. If volatility asymmetry exists, the slope of each side of the "V" shape should be different. With this idea, to test the asymmetry, an econometric model is constructed as Model (1).

$\operatorname{Model}(1): \quad R V_{t}=\omega+\beta_{0} R V_{t-1}+\sum_{i=1}^{p} \alpha_{i} R_{t-i}^{-}+\sum_{j=1}^{q} \lambda_{i} R_{t-j}^{+}+\varepsilon_{t}$

Here, $\omega, \beta_{0}, \alpha_{i}$ and $\lambda_{i}$ are parameters to be estimated. $R_{t}$, $R V_{t}$ are respectively the daily return and daily $R V_{t} ; p$ and $q$ are the orders of lags. $R_{t}^{-}$and $R_{t}^{+}$are respectively defined as,

$$
R_{t}^{+}=\left\{\begin{array}{ll}
R_{t} & \text { if } R_{t}>0 \\
0 & \text { otherwise }
\end{array} \quad R_{t}^{-}= \begin{cases}R_{t} & \text { if } R_{t}<0 \\
0 & \text { otherwise }\end{cases}\right.
$$

In addition, another model combing with the idea of EGARCH (Nelson (1991)) model and realized volatility is constructed as $\operatorname{Model}(2)$,

$$
\begin{aligned}
\operatorname{Model}(2): \quad \ln R V_{t}^{2}= & \omega+\beta_{0} R V_{t-1}^{2}+\alpha_{1} \frac{R_{t-1}^{-}}{\sqrt{R V_{t-1}^{2}}} \\
& +\lambda_{1} \frac{R_{t-1}^{+}}{\sqrt{R V_{t-1}^{2}}}+\varepsilon_{t}
\end{aligned}
$$

The definition of variables in $\operatorname{Model}(2)$ is the same as that in Model(1). The estimation results of Model(1) and Model(2) are shown in Table 2.

In Table 2, negative $\alpha_{i}$ and positive $\lambda_{j}$ indicate that both too-high and too-low of return will lead to higher volatility, which is consistent with the "V" shape relationship between return and volatility, as shown in figure 4. However, the Wald tests (Greene (2003)) of coefficients equality, as shown in Table 3, indicate there is no significant difference between the two slopes. This means the leverage effect or

Table 2. Estimation results for testing of asymmetry with econometric models

\begin{tabular}{lcccccc}
\hline Coefficient & $\omega$ & $\beta_{0}$ & $\alpha_{1}$ & $\lambda_{1}$ & $\alpha_{2}$ & $\lambda_{2}$ \\
\hline Model $(1)^{a}$ & 0.0008 & 0.1267 & -0.2268 & 0.1627 & & \\
& $(0.0000)$ & $(0.0343)$ & $(0.0004)$ & $(0.0036)$ & & \\
$\operatorname{Model}(1)^{b}$ & 0.0007 & -.0976 & -0.2224 & 0.1518 & -0.0900 & 0.1180 \\
& $(0.0000)$ & $(0.1080)$ & $(0.0067)$ & $(0.0008)$ & $(0.1291)$ & $(0.0161)$ \\
$\operatorname{Model}(1)^{c}$ & 0.0007 & 0.01109 & -0.2454 & 0.1523 & & 0.0914 \\
& $(0.0000)$ & $(0.0655)$ & $(0.0002)$ & $(0.0066)$ & & $(0.0460)$ \\
$\operatorname{Model}(2)$ & -9.4032 & -.3502 & -0.3091 & 0.2843 & & \\
& $(0.0000)$ & $(0.0000)$ & $(0.0063)$ & $(0.0032)$ & & \\
\hline
\end{tabular}

Here, estimation results of model (1) and model (2) are shown. Model $(1)^{a}$, model $(1)^{b}$ and model $(1)^{c}$ are respectively one of the special specifications of model (1) with different lag numbers of $p$ and $q$. New-west adjustment is applied in the model estimation, and the values in the parentheses are the p-values of the coefficients. 
Table 3. P-values for Wald test on coefficients equality

\begin{tabular}{lcccc}
\hline P-value & Model $(1)^{a}$ & $\operatorname{Model}(1)^{b}$ & $\operatorname{Model}(1)^{c}$ & $\operatorname{Model}(2)$ \\
\hline$H_{0} \alpha_{1}=-\lambda_{1}$ & 0.27 & 0.25 & 0.12 & 0.81 \\
$H_{0} \alpha_{2}=-\lambda_{2}$ & & 0.65 & & \\
\hline
\end{tabular}

Here the results for Wald tests of coefficients in model (1) and model (2) are shown. Model $(1)^{a}$, model $(1)^{b}$ and model $(1)^{c}$ are respectively one of the special specification of model (1) with different lag numbers of $p$ and $q$. The values in the table are the p-values of related Wald tests.

volatility asymmetry is insignificant in CTBM. ${ }^{5}$ Moreover, it's interesting that the effect of positive return on volatility will persist for two days, but the influence of negative return may persist only one day.

Here, the most important conclusion about the econometric testing of volatility asymmetry is that negative and positive innovations have no different impact on future volatility, which is different from the results found in other markets, such as Engle (2004)'s tests on S\&P 500 stocks, Andersen et al. (2003) and Wang and Yang (2006)'s tests on foreign exchange market. The chief reason responsible for these special results would be the special background of the market. It should be noted that there is no fixed time and specified term for the Treasury bond issuing in China, which is usually only serviced for the irregularly demand of macroeconomic control, such as increasing the government payment, and the adjustment of the currency demand or supply. The total number of Treasury bonds outstanding is usually less than 100. For these special facts, compared with other markets, there could be not so many investors trading actively in the Treasury bond market, and the information come to this market slowly. That is, price discovering in the Chinese Treasury bond market is not as efficient as other markets.

With respect to the volatility asymmetry, though econometrical insignificant, does it provide useful information to volatility forecasting? The tests in the following sections will bring interesting answers.

\section{VOLATILITY FORECASTING: TO TEST THE ASYMMETRY FURTHER}

Volatility forecasting is helpful for risk management as well asset pricing. In this chapter, analysis on volatility forecasting is provided to further test the volatility asymmetry in CTBM. A various of volatility models are presented firstly, and then their asymmetric counterparts are proposed. After that, the empirical results of CTBM will show that models with asymmetric specifications have better forecasting ability even the asymmetry is rejected in traditional tests.

\footnotetext{
${ }^{5}$ The asymmetry testing results with EGARCH model are not presented here and will be presented in detail in the next section in this paper.
}

\subsection{Some classical volatility model}

\subsubsection{Model introduction}

ARCH-family models To model the time-varying volatility, or the autocorrelation of the second moment of returns, Engle (1982) proposes ARCH model. Typically, an ARCH (p) model is defined as,

$$
\begin{aligned}
r_{t} & =a+b r_{t-1}+\varepsilon_{t}, \operatorname{Var}\left(\varepsilon_{t} \mid \Omega_{t-1}\right)=h_{t}, \\
h_{t} & =\omega+\sum_{i=1}^{p} \alpha_{i} \varepsilon_{t-i}^{2}
\end{aligned}
$$

Here, $\Omega_{t-1}$ represents the information set at time $t-1$. Compared with the former models, ARCH model can capture the volatility clustering dynamics in the financial markets. Based on the ARCH model, Bollerslev (1986) proposes the generalized $\mathrm{ARCH}$ model (GARCH). The variance equation of a $\operatorname{GARCH}(p, q)$ model is,

$$
h_{t}=\omega+\sum_{i=1}^{p} \alpha_{i} \varepsilon_{t-i}^{2}+\sum_{j=1}^{q} \beta_{i} h_{t-j}
$$

In the GARCH model, the error squares of return expectation, $\varepsilon_{t-i}^{2}$, reflect the effects of new-arrival information on future volatility, and the delayed conditional variance, $h_{t-j}$, reflects the long-term movement of volatility. The variance equation of a $\operatorname{GARCH}(1,1)$ model is,

$$
h_{t}=\omega+\alpha_{1} \varepsilon_{t-1}^{2}+\beta_{1} h_{t-1}
$$

To describe the volatility asymmetry, Nelson (1991) proposed the EGARCH mode. The variance equation of an EGARCH $(1,1)$ model is,

$$
\ln h_{t}=\omega+\alpha\left|\frac{\varepsilon_{t-1}}{h_{t-1}^{1 / 2}}\right|+\gamma \frac{\varepsilon_{t-1}}{h_{t-1}^{1 / 2}}+\beta \ln h_{t-1}
$$

In addition to the EGARCH, there are also some other asymmetric ARCH-family models such as TARCH (Zakoian (1994)), or GJR (Glosten et al. (1993)). In this paper, EGARCH model is selected as the representative of these asymmetric models.

ARMA model Omen (2001) has shown that modeling intra-day returns as an ARMA process is a natural and successful choice because ARMA model is well suited to account for the serial dependence of returns at various sampling frequencies. For an ARMA model, the AR part will arguably be able to capture any autocorrelation induced by non-synchronous trading while the MA part will account for potential negative first order autocorrelation induced by the bid-ask bounce. Moreover, at higher sampling frequencies the ARMA model can account for the observed serial dependence while at lower sampling frequencies these dependencies die off as a consequence of temporal aggregation 
of the return process. Similarly, to describe the autocorrelation dependence of the volatility, the ARMA type models are applied directly to the realized volatility. An ARMA model can be described as,

$$
\phi(L) y_{t}=\theta(L) \varepsilon_{t}
$$

Here, $y_{t}$ is the observed series, realized volatility $R V_{t}$ in this paper. $\phi(L), \theta(L)$ are respectively the $p$-order and $q$ order lag operator.

Heterogeneous model Autoregressive model assuming the heterogeneity of the market investors is proposed by Corsi (2003). The basic idea of the heterogeneous autoregressive (HAR) volatility model is that there are many types of investors in the market, and each has its regular trading time interval. For example, it is usually hypothesized that there are three types of investors with daily (short term), weekly (medium term) and monthly (long term) trading interval, and a HAR model is constructed as,

$$
R V_{t}=a+b R V_{t-1}+c R V_{t-5, t}+d R V_{t-22, t}+\varepsilon_{t}
$$

Here, $(\mathrm{d}, \mathrm{w}, \mathrm{m})$ means the HAR model has included the effects of the three types of investors with daily, weekly ( 5 trading days a week) and monthly (22 trading days a month) trading interval; $b R V_{t-1}, R V_{t-5, t}$ and $R V_{t-22, t}$ respectively represent daily realized volatility at day $t-1$, the weekly and monthly realized volatility previous time $t$ to capture the contributions for different types of investors; If only two types of investors are assumed, daily and monthly for example, the model can be constructed as,

$$
R V_{t}=a+b R V_{t-1}+d R V_{t-22, t}+\varepsilon_{t}
$$

With the heterogeneous models, empirical studies on CTBM here will bring us more learning on the market volatility and heterogeneity.

Volatility models combining with GARCH model and realized volatility GARCH model and realized volatility are two different ways of volatility modeling. Then, the direct question is that whether the two models or methods can work together to use both the structure of ARCH model and the information of inter-day data, or whether the realized volatility is helpful for modeling and forecasting conditional volatility. This paper introduces realized volatility into GARCH model, and a new volatility model named RVGARCH is constructed. Our work is also built on the former work of Blair et al. (2001), and Hol and Koopman (2002), in which the lagged realized volatility is introduced into the variance equation of GARCH model. The variance equation of RV-GARCH model can be transformed to,

$$
h_{t}=\omega+\alpha \varepsilon_{t-1}^{2}+\xi\left(R V_{t-1}^{2}-h_{t-1}\right)+(\xi+\beta) h_{t-1}
$$

The term $M=\xi\left(R V_{t-1}^{2}-h_{t-1}\right)+(\xi+\beta) h_{t-1}$ is an ARMA process of $h_{t}$ with the hypothesis that realized volatility is the volatility benchmark (truly one). The autoregressive part $(\xi+\beta) h_{t-1}$ represents the long-term trend of the volatility, and the moving average part $\xi\left(R V_{t-1}^{2}-h_{t-1}\right)$ is viewed as the short-term movement of volatility. Then, the variance equation of RV-GARCH model includes three factors that contribute to the future volatility, one long-term factor and two short-term factors. The long-term factor is the autoregressive term $h_{t-1}$ and the short-term factors includes (square) forecasting error of conditional mean $\varepsilon_{t-1}^{2}$ and forecasting error of conditional variance $\left(R V_{t-1}^{2}-h_{t-1}\right)$.

The same as RV-GARCH, introducing realized volatility into EGARCH model to capture the volatility asymmetry, variance equation of RV-EGARCH model can be constructed as follows,

$$
\ln h_{t}=\omega+\alpha\left|\frac{\varepsilon_{t-1}}{h_{t-1}^{1 / 2}}\right|+\gamma \frac{\varepsilon_{t-1}}{h_{t-1}^{1 / 2}}+\beta \ln h_{t-1}+\xi R V_{t-1}^{2}
$$

The process from RV-GARCH to RV-EGARCH is so similar, and it is not discussed in detail here.

\subsection{Empirical models with or without asymmetry}

\subsubsection{Empirical models without asymmetry}

Four types of volatility models are mentioned above, the ARCH-family models, the ARMA type models, the heterogeneous models HRV, and models combining with ARCHfamily model and realized volatility. Without considering the asymmetry, these models are sorted as follows.

\section{ARCH-family model without asymmetry}

$$
\begin{aligned}
\operatorname{GARCH}^{(1,1)}: & r_{t}=a+b r_{t-1}+\varepsilon_{t}, \operatorname{Var}\left(\varepsilon_{t} \mid \Omega_{t-1}\right)=h_{t}, \\
& h_{t}=\omega+\alpha_{1} \varepsilon_{t-1}^{2}+\beta_{1} h_{t-1}
\end{aligned}
$$

Here, GARCH $(1,1)$ is selected as the representative model of ARCH-family models without asymmetry because it is the most popular model, also generally the best one, applied in practice (Bollerslev et al. (1992); Hansen and Lunde (2005)).

\section{ARMA type models without asymmetry}

$$
\begin{array}{cc}
\mathrm{MA}^{(1)}: & R V_{t}=a+\varepsilon_{t}+b \varepsilon_{t-1} \\
\mathrm{AR}^{(1,5,8)}: & R V_{t}=a+b R V_{t-1}+c R V_{t-5}+c R V_{t-8} \\
& +\lambda\left|r_{t-1}\right|+\varepsilon_{t}
\end{array}
$$

The MA (1) model is selected because only the first lag of the moving averages is significant. Even the coefficient of AR part is insignificant in the ARMA $(1,1)$ model. In AR $(1,5,8)$ model, the lag orders are selected according to the autocorrelation and partial autocorrelation of $R V_{t}$, and other lags less than 8 is insignificant. Adding $\left|r_{t-1}\right|$ into the model is just for comparing with the asymmetric counterpart shown in section 4 . 
Heterogeneous models without asymmetry

$$
\begin{array}{rrr}
\mathrm{HAR}^{(\mathrm{d}, \mathrm{w}, \mathrm{m})}: & R V_{t}=a+b R V_{t-1}+c R V_{t-5}+c R V_{t-22} \\
& +\lambda\left|r_{t-1}\right|+\varepsilon_{t}
\end{array}
$$

Because it is not known whether all of the three types of investors exist in CTBM, three additional HAR models are considered to reflect the situation that there are only two types of investors. Here, the definition of each model is similar to that of Eq. (16) and Eq. (17).

\section{$R V-G A R C H$ model without asymmetry}

$$
\begin{array}{ll}
\mathrm{RV}-\mathrm{GARCH}^{(1,1)}: \quad & r_{t}=a+b r_{t-1}+\varepsilon_{t}, \operatorname{Var}\left(\varepsilon_{t} \mid \Omega_{t-1}\right)=h_{t}, \\
h_{t} & =\omega+\alpha \varepsilon_{t-1}^{2}+\beta h_{t-1}+\xi R V_{t-1}^{2}
\end{array}
$$
$R V$.

Here, GARCH $(1,1)$ model is selected to be in pairs with

\subsubsection{Empirical models with asymmetry}

Now, additional asymmetric models are constructed that are counterparts of the models (without asymmetry) mentioned above. These asymmetric models include,

Asymmetric ARCH-family models (EGARCH)

$$
\begin{array}{ll}
\operatorname{EGARCH}^{(1,1)}: \quad & r_{t}=a+b r_{t-1}+\varepsilon_{t}, \operatorname{Var}\left(\varepsilon_{t} \mid \Omega_{t-1}\right)=h_{t}, \\
& \ln h_{t}=\omega+\alpha\left|\frac{\varepsilon_{t-1}}{h_{t-1}^{1 / 2}}\right|+\gamma \frac{\varepsilon_{t-1}}{h_{t-1}^{1 / 2}}+\beta \ln h_{t-1}
\end{array}
$$

Here, EGARCH model is selected as the representative of asymmetric ARCH-family models.

Asymmetric ARMA type models

$$
\begin{aligned}
& \mathrm{N}-\mathrm{MA}^{(1)}: \quad R V_{t}=a+\varepsilon_{t}+b \varepsilon_{t-1}+\lambda r_{t-1} D_{t-1} \\
& +\gamma r_{t-1} U_{t-1} \\
& \mathrm{~N}-\mathrm{AR}^{(1,5,8)}: \quad R V_{t}=a+b R V_{t-1}+c R V_{t-5}+c R V_{t-8} \\
& +\lambda r_{t-1} D_{t-1}+\gamma r_{t-1} U_{t-1}+\varepsilon_{t}
\end{aligned}
$$

Hereafter, if $\varepsilon_{t-1}<0, D_{t-1}=1$, otherwise $D_{t-1}=0$; $U_{t-1}=1-D_{t-1}$

Asymmetric Heterogeneous models

$$
\begin{aligned}
& \text { N-HAR }{ }^{(\mathrm{d}, \mathrm{w}, \mathrm{m})}: \quad R V_{t}=a+b R V_{t-1}+c R V_{t-5}+c R V_{t-22} \\
& +\lambda r_{t-1} D_{t-1}+\gamma r_{t-1} U_{t-1}+\varepsilon_{t} \\
& \mathrm{~N}-\mathrm{HAR}^{(\mathrm{d}, \mathrm{m})}: \quad R V_{t}=a+b R V_{t-1}+c R V_{t-22} \\
& +\lambda r_{t-1} D_{t-1}+\gamma r_{t-1} U_{t-1}+\varepsilon_{t}
\end{aligned}
$$

Models combining asymmetric GARCH with $R V$

$$
\begin{gathered}
\operatorname{EGARCH}^{(1,1)}: \quad r_{t}=a+b r_{t-1}+\varepsilon_{t}, \operatorname{Var}\left(\varepsilon_{t} \mid \Omega_{t-1}\right)=h_{t}, \\
\qquad \begin{array}{c}
\ln h_{t}=\omega+\alpha\left|\frac{\varepsilon_{t-1}}{h_{t-1}^{1 / 2}}\right|+\gamma \frac{\varepsilon_{t-1}}{h_{t-1}^{1 / 2}}+\beta \ln h_{t-1} \\
+\xi R V_{t-1}^{2}
\end{array}
\end{gathered}
$$

All the models mentioned above could be classified into two groups, models with asymmetry and models without asymmetry. In each class, there are four types of models, ARCH-family models based on return series, ARMA and HAR models based on realized volatility, and RV-GARCH type models based on both return and realized volatility.

\subsection{Model estimation and forecasting comparison}

\subsubsection{Model estimation}

The estimation output of all the models mentioned above is shown in Table 4.

The model estimation output shown in Table 4 indicates, once more, that the asymmetry is insignificant in CTBM. For example, the coefficient representing asymmetry in EGARCH model, $\gamma$, is insignificant, and the hypotheses that the influence of positive and negative innovations on future volatility is equivalent can not be rejected with high p-value in the Wald tests. Moreover, according to the results of HAR models, there are evidences to support the conclusion that the medium-term investor who trade with weekly interval regularly is not clear, but short-term (daily) and long-term (monthly) investors are rather important.

\subsubsection{Volatility forecasting comparison}

This section focuses on the forecasting ability between symmetric and asymmetric models. Here, the data of the former 351 days (from Jun.1 2004 through Oct.31 2005) is used to estimate models and the last 40 days (the last two months) is left as the forecasting evaluation period. RMSE, MAE, MAPE and Theil coefficients for each model are listed in Table 5 with benchmark of ex-post realized volatility $R V_{t}$. The forecasting method employed here is the one-step static forecast.

Different from section 3 and 5.3.1, the main conclusion drawn from Table 5 is that all asymmetric models are better in volatility forecasting than their symmetric counterparts. The forecasting errors are reduced when the different effects of positive and negative returns on future volatility are considered. That is, asymmetry specifications provide important and indispensable information for volatility forecasting though it is marginal in the econometric tests shown in section 3. For forecasting ability of all the models, the RV$\operatorname{EGARCH}(1,1), \mathrm{N}-\mathrm{AR}(1,5,8)$ and $\mathrm{N}-\mathrm{MA}(1)$ model behave better. 
Table 4. Estimation results for the volatility models

\begin{tabular}{|c|c|c|c|c|c|c|c|}
\hline \multicolumn{8}{|c|}{ ARCH-family models and RV-ARCH models } \\
\hline Model & $a$ & $b$ & $\omega$ & $\alpha$ & $\beta$ & $\zeta$ & $\gamma$ \\
\hline $\mathrm{GARCH}^{(1,1)}$ & $\begin{array}{c}0.0003 \\
(0.0008)\end{array}$ & $\begin{array}{c}0.3179 \\
(0.0000)\end{array}$ & $\begin{array}{c}1.26 \times 10^{-7} \\
(0.0102)\end{array}$ & $\begin{array}{c}0.1441 \\
(0.0001)\end{array}$ & $\begin{array}{c}0.7815 \\
(0.0000)\end{array}$ & & \\
\hline $\mathrm{EGARCH}^{(1,1)}$ & $\begin{array}{c}0.0003 \\
(0.0025)\end{array}$ & $\begin{array}{c}0.3367 \\
(0.0000)\end{array}$ & $\begin{array}{c}-1.5834 \\
(0.0029)\end{array}$ & $\begin{array}{c}0.2499 \\
(0.0000)\end{array}$ & $\begin{array}{c}0.8964 \\
(0.0000)\end{array}$ & & $\begin{array}{r}-0.1077 \\
(0.6265)\end{array}$ \\
\hline RV-GARCH ${ }^{(1,1)}$ & $\begin{array}{c}0.0003 \\
(0.0002)\end{array}$ & $\begin{array}{c}0.3371 \\
(0.0000)\end{array}$ & $\begin{array}{c}1.01 \times 10^{-7} \\
(0.0412)\end{array}$ & $\begin{array}{c}0.1664 \\
(0.0116)\end{array}$ & $\begin{array}{c}0.5859 \\
(0.0000)\end{array}$ & $\begin{array}{c}0.1954 \\
(0.0006)\end{array}$ & \\
\hline RV-EGARCH ${ }^{(1,1)}$ & $\begin{array}{c}0.0003 \\
(0.0013)\end{array}$ & $\begin{array}{c}0.3321 \\
(0.0000)\end{array}$ & $\begin{array}{l}-6.3 .68 \\
(0.0000)\end{array}$ & $\begin{array}{c}0.3236 \\
(0.0018)\end{array}$ & $\begin{array}{c}0.5607 \\
(0.0000)\end{array}$ & $\begin{array}{c}76525 \\
(0.0003)\end{array}$ & $\begin{array}{r}-0.1222 \\
0.0574\end{array}$ \\
\hline \multicolumn{8}{|c|}{ ARMA type models } \\
\hline Model & $a$ & $b$ & $c$ & $d$ & $\lambda$ & $\gamma$ & Test: $\lambda=-\gamma$ \\
\hline $\mathrm{MA}^{(1)}$ & $\begin{array}{c}0.0011 \\
(0.0000)\end{array}$ & $\begin{array}{c}0.2209 \\
(0.0000)\end{array}$ & & & & & - \\
\hline $\mathrm{N}-\mathrm{MA}^{(1)}$ & $\begin{array}{c}0.0009 \\
(0.0000)\end{array}$ & $\begin{array}{c}0.0195 \\
(0.1813)\end{array}$ & & & $\begin{array}{c}-0.2430 \\
(0.0001)\end{array}$ & $\begin{array}{c}0.1800 \\
(0.0010)\end{array}$ & 0.2426 \\
\hline $\operatorname{AR}^{(1,5,8)}$ & $\begin{array}{c}0.0005 \\
(0.0000)\end{array}$ & $\begin{array}{c}0.1346 \\
(0.0119)\end{array}$ & $\begin{array}{c}0.1080 \\
(0.0579)\end{array}$ & $\begin{array}{c}0.1026 \\
(0.0721)\end{array}$ & $\begin{array}{c}0.1462 \\
(0.0119)\end{array}$ & & - \\
\hline $\mathrm{N}-\mathrm{AR}^{(1,5,8)}$ & $\begin{array}{c}0.0009 \\
(0.0000)\end{array}$ & $\begin{array}{c}0.1335 \\
(0.0287)\end{array}$ & $\begin{array}{c}0.1068 \\
(0.0359)\end{array}$ & $\begin{array}{c}0.1006 \\
(0.0491)\end{array}$ & $\begin{array}{c}-0.1904 \\
(0.0051)\end{array}$ & $\begin{array}{c}0.1310 \\
(0.0287)\end{array}$ & 0.2077 \\
\hline \multicolumn{8}{|c|}{ Heterogeneous model HAR } \\
\hline Model & $a$ & $b$ & $c$ & $d$ & $\lambda$ & $\gamma$ & Test: $\lambda=-\gamma$ \\
\hline $\operatorname{HAR}^{(d, w, m)}$ & $\begin{array}{c}0.0005 \\
(0.0054)\end{array}$ & $\begin{array}{c}0.1147 \\
(0.1127)\end{array}$ & $\begin{array}{r}-0.0015 \\
(0.9909)\end{array}$ & $\begin{array}{c}0.2865 \\
(0.1646)\end{array}$ & $\begin{array}{c}0.1154 \\
(0.0123)\end{array}$ & & \\
\hline N-HAR ${ }^{(d, w, m)}$ & $\begin{array}{c}0.0005 \\
(0.0033)\end{array}$ & $\begin{array}{c}0.1083 \\
(0.1127)\end{array}$ & $\begin{array}{c}-0.0039 \\
(0.9909)\end{array}$ & $\begin{array}{c}0.3096 \\
(0.1646)\end{array}$ & $\begin{array}{r}-0.2097 \\
(0.0123)\end{array}$ & $\begin{array}{c}0.1450 \\
(0.0144)\end{array}$ & 0.2936 \\
\hline $\operatorname{HAR}^{(d, m)}$ & $\begin{array}{c}0.0005 \\
(0.0061)\end{array}$ & $\begin{array}{r}0.11297 \\
(0.0995)\end{array}$ & & $\begin{array}{c}0.2999 \\
(0.0814)\end{array}$ & $\begin{array}{c}0.1509 \\
(0.0135)\end{array}$ & & \\
\hline $\mathrm{N}-\mathrm{HAR}^{(d, m)}$ & $\begin{array}{c}0.0005 \\
(0.0033)\end{array}$ & $\begin{array}{c}0.1083 \\
(0.1127)\end{array}$ & & $\begin{array}{c}0.3095 \\
(0.0412)\end{array}$ & $\begin{array}{c}-0.2095 \\
(0.0021)\end{array}$ & $\begin{array}{c}0.1449 \\
(0.0142)\end{array}$ & 0.2932 \\
\hline
\end{tabular}

The estimation results for all volatility models are shown here, including four types of models, ARCH-family models based on return series, ARMA and HAR models based on realized volatility, and RV-GARCH type models based on both return and realized volatility. The empirical tests find that only the daily and monthly components are significant in the HAR model, and other models such as $\operatorname{HAR}^{(w, m)}$ and $\operatorname{HAR}^{(d, w)}$ will produce one or more coefficient insignificant, so only results of $\mathrm{HAR}^{(d, m)}$ model are shown here. More introductions of the models are shown in section 5.2. The values in the parentheses are the p-values of the coefficient estimators.

Two reasons may contribute to the fact that volatility asymmetry is insignificant in the econometric tests specifications while it also provides important and indispensable information for volatility forecasting.

Firstly, factors affecting valuation of Treasury bonds are much different from that of stocks or currencies, and price discovering in the Treasury bond market is also special. Comparing with the stock market, less private information exists in the Treasury bond market, and comparing with the exchange market, fewer international impact or news may affect the Treasury bond market. For nearly no default risk, the cash flow of the Treasury bonds are almost fixed. The valuation of Treasury bonds mainly depends on the discount rate or the interest rate risk, which is mostly related to the monetary policies or other related macro-variables, such as CPI, the supply of the currency and so on. However, these variables or policies are rather stable and not varied sharply or frequently in a short time interval. So, comparing with the volatility in stock or exchange market, there are not so many information-based impacts in the Treasury bond market.

Secondly, for the special background of the Chinese Treasury bond market and the structure of investors in the stock market, information in other markets, such as the stock market, can not be transferred to the Treasury market either. Two factors may be responsible for it.

On the one hand, the trading in CTBM is not very active and the market is not so liquid as the stock market or as the US Treasury bond market. For example, number of trades for all the Treasury bonds in Shanghai Security Exchange (SHSE) market is less than 500,000 over 2004 to 2006, but one stock in SHSE may have more than 1,000,000 trades during the same period. In the meanwhile, many recent works find that liquidity cost is included in the bond 
Table 5. Comparison of forecasting ability

\begin{tabular}{|c|c|c|c|c|}
\hline Model & RMSE & MAE & MAPE & Theil \\
\hline $\mathrm{GARCH}^{(1,1)}$ & 0.000651 & 0.000449 & 43.92 & 0.229542 \\
\hline $\mathrm{EGARCH}^{(1,1)}$ & 0.000634 & 0.000441 & 42.22 & 0.229532 \\
\hline $\mathrm{MA}^{(1)}$ & 0.000675 & 0.000479 & 38.88 & 0.261948 \\
\hline $\mathrm{N}-\mathrm{MA}^{(1)}$ & 0.000642 & 0.000444 & 35.44 & 0.247508 \\
\hline $\operatorname{AR}^{(1,5,8)}$ & 0.000631 & 0.000432 & 36.67 & 0.237013 \\
\hline $\mathrm{N}-\mathrm{AR}^{(1,5,8)}$ & 0.000612 & 0.000413 & 35.47 & 0.228165 \\
\hline $\operatorname{HAR}^{(d, w, m)}$ & 0.000623 & 0.000452 & 29.64 & 0.231835 \\
\hline $\mathrm{N}^{-H_{A R}}{ }^{(d, w, m)}$ & 0.000616 & 0.000443 & 39.45 & 0.227563 \\
\hline $\operatorname{HAR}^{(d, m)}$ & 0.000622 & 0.000452 & 39.93 & 0.231232 \\
\hline $\mathrm{N}_{-} \mathrm{HAR}^{(d, m)}$ & 0.000616 & 0.000443 & 39.40 & 0.227766 \\
\hline RV-GARCH ${ }^{(1,1)}$ & 0.000642 & 0.000433 & 43.17 & 0.222072 \\
\hline RV-EGARCH ${ }^{(1,1)}$ & 0.000606 & 0.000422 & 39.87 & 0.217963 \\
\hline
\end{tabular}

Here, the forecasting errors for all the volatility models are shown. The data of the former 351 days (from Jun.1 2004 through Oct.31 2005) are used to estimate the models and the last 40 days (the last two months) is left as the forecasting section. RMSE, MAE, MAPE and Theil coefficients for each model are listed in the table with benchmark of ex-post realized volatility $R V_{t}$. More introductions of the models are shown in section 5.2.

price. So, as shown in Lesmond et al. (1999), if the value of a information signal is not enough to compensate the costs of trading, then the marginal investor will either reduce trading or don't trade. The illiquid Chinese Treasury bond market induce higher trading cost, so only the big news may have significant impact on the price, but in other times, the price change is mostly due to the liquidity cost, just as the roundtrip trading cost of Schultz (2001), or the concession cost of Harris and Piwowar (2006), Edwards et al. (2007).

On the other hand, in the Chinese stock market, most of the investors are individual ones. More than $90 \%$ individual investors hold $51.29 \%$ of the total market share at the end of 2007. Their ability to take cross-market asset allocation and risk hedging may be much weaker than that of the institutional investors, and most of them take little cross-market asset allocation between stock and bond market, but between stock market and bank accounts. For these reasons, compared with the stock or foreign exchange market, not only fewer information-based impacts affect the market volatility, the information in stock market also can not be transferred to Treasury market for the special background of the capital market in China.

As a result of special pricing discovering in the Treasury bond market, as well as of the Chinese stock and Treasury market background, the information-based impacts in CTBM are not as common as that in the stock or foreign exchange market. Some hypotheses about the source of volatility asymmetry, such as leverage effect or feedback effect, emphasize the role of information in pricing discovering. The results shown in this paper indicate that there is something different for the role of volatility asymmetry in (Treasury) bond and stock market. The insignificance of volatility asymmetry in the Treasury bond market may come from the special way of bond pricing and total capital market background in China. However, the asymmetry effect of impacts related to the discount rate may be also important and helpful to the volatility forecasting. The accuracy of volatility forecasting for the big news is the key factor and most important for a successful volatility model though these events are not taking place often. So, when considering volatility symmetry, the models always behave better.

In an attempt to explain why asymmetry property is indispensable for volatility forecasting though it is marginal significant, Monte Carlo simulations are provided in the next section.

\section{SIMULATIONS: THE ROLE OF ASYMMETRY IN VOLATILITY MODELLING}

To reinforce the empirical results concerning about the role of asymmetry in volatility modelling, Monte Carlo simulations are provided here. The steps of simulation are as follows.

(1) High-frequency return series $r_{t, i}$ are simulated with a GARCH process, including total 48,000 returns for 1,000 days, 48 five-minute returns each day.

(2) Compute the daily realized volatility $R V_{t}$ and daily returns $R_{t}, T=1,2, \ldots, 1000$, with the simulated series $r_{t, i}$. When computing the realized volatility, the MA (1) filters of Andersen et al. (2001) is used to remove the first-order autocorrelation of the original series.

(3) Model the daily return series $R_{t}$ with GARCH, EGARCH, RV-GARCH, RV-EGARCH, AR, N-AR, HAR and N-HAR model, and then to compute the conditional volatility $\sigma_{t}^{k}\left(\sigma_{t}^{G A R C H}, \sigma_{t}^{E G A R C H}\right.$, $\sigma_{t}^{R V-G A R C H}, \sigma_{t}^{R V-E G A R C H}, \sigma_{t}^{A R}, \sigma_{t}^{N-A R}, \sigma_{t}^{H A R}$ and $\sigma_{t}^{N-H A R}$ ) as well as the standardized return series $\varepsilon_{t}^{k}=R_{t} / \sigma_{t}^{k}$.

(4) Compare the normality of $\varepsilon_{t}^{k}$ by using the statistics of mean, median, min, max, standard error, skew, kurtosis and J-B value. Under the hypothesis that return series conforms to process $R_{t}=\varepsilon_{t} \sigma_{t}\left(\varepsilon_{t} \sim N(0,1)\right), \varepsilon_{t}^{k}$ will be close to normal if $\sigma_{t}^{k}$ is a good measure of volatility. Here, the kurtosis that describes the probability of extreme value is the chief statistic to compare, because high kurtosis usually means high probability of extreme events and "fat tail" of the return.

(5) Repeat step (1) to step (4) $N$ times (10,000 times this paper) to get the average value of the above statistics.

The simulation results are shown in Table 6 . The most important thing that should be concentrated on is the difference between each model and its asymmetric counterpart, with which to discover the role of asymmetry in volatility modelling.

Simulation result of Table 6, once again, show that though the original simulated series have no asymmetry, all 
Table 6. Statistics of simulated series

\begin{tabular}{|c|c|c|c|c|c|c|c|c|}
\hline \multicolumn{9}{|c|}{$\begin{array}{l}\text { Model to produce original high frequency series: } \\
r_{t}=\varepsilon_{t}, E\left(\varepsilon_{t}^{2} \mid \Omega_{t-1}\right)=0.005+0.1 \varepsilon_{t-1}^{2}+0.89 h_{t-1}\end{array}$} \\
\hline Model & Mean & Median & Min & Max & Std & Skew & Kurtosis & J-B \\
\hline Original & -0.0023 & -0.0004 & -26.5503 & 26.3783 & 3.9958 & -0.0077 & 9.1528 & 12713 \\
\hline GARCH & -0.0005 & -0.0001 & -5.2407 & 5.2407 & 1.0006 & -0.0023 & 5.1962 & 580.34 \\
\hline EGARCH & -0.0005 & -0.0001 & -5.2373 & 5.2232 & 1.0003 & -0.0024 & 5.1752 & 548.07 \\
\hline RV-GARCH & -0.0004 & -0.0002 & -4.3387 & 4.3130 & 1.0004 & -0.0034 & 3.8398 & 72.71 \\
\hline RV-EGARCH & -0.0004 & -0.0002 & -4.2445 & 4.2177 & 1.0004 & -0.0025 & 3.7570 & 59.11 \\
\hline AR & -0.0004 & -0.0002 & -4.4624 & 4.4249 & 1.0454 & -0.0029 & 3.7669 & 60.59 \\
\hline N-AR & -0.0004 & -0.0002 & -4.4664 & 4.4266 & 1.0456 & -0.0029 & 3.7675 & 60.67 \\
\hline HAR & -0.0003 & -0.0002 & -4.6423 & 4.6236 & 1.0808 & -0.0023 & 3.8145 & 68.30 \\
\hline N-HAR & -0.0004 & -0.0002 & -4.4495 & 4.4183 & 1.0449 & -0.0028 & 3.7555 & 59.11 \\
\hline \multicolumn{9}{|c|}{$\begin{array}{l}\text { Model to produce original high frequency series: } \\
r_{t}=0.3 r_{t-1}+\varepsilon_{t}, E\left(\varepsilon_{t}^{2} \mid \Omega_{t-1}\right)=0.005+0.14 \varepsilon_{t-1}^{2}+0.78 h_{t-1}\end{array}$} \\
\hline Original & 0.0000 & 0.0000 & -0.3122 & 0.3081 & 0.0642 & -0.0042 & 4.4208 & 244.91 \\
\hline GARCH & -0.0004 & 0.0001 & -4.7457 & 4.6984 & 1.0008 & -0.0036 & 4.2823 & 19.8483 \\
\hline EGARCH & -0.0004 & 0.0001 & -4.7216 & 4.6781 & 1.0006 & -0.0038 & 4.2622 & 173.70 \\
\hline RV-GARCH & -0.0004 & 0.0001 & -4.4924 & 4.4411 & 0.9972 & -0.0048 & 4.0338 & 363.13 \\
\hline RV-EGARCH & -0.0004 & 0.0001 & -4.4704 & 4.4284 & 1.0010 & -0.0025 & 3.9520 & 95.11 \\
\hline AR & -0.0006 & 0.0001 & -7.0288 & 6.9977 & 1.4665 & -0.0018 & 4.3617 & 262.96 \\
\hline N-AR & -0.0006 & 0.0001 & -6.4841 & 6.4209 & 1.4359 & -0.0032 & 4.0075 & 109.80 \\
\hline HAR & -0.0006 & 0.0001 & -6.5109 & 6.4359 & 1.4369 & -0.0059 & 4.0736 & 859.83 \\
\hline N-HAR & -0.0006 & 0.0001 & -6.4442 & 6.3737 & 1.4296 & -0.0030 & 3.9848 & 104.340 \\
\hline
\end{tabular}

Here, the Monte Carlo simulation results for the role of volatility asymmetry are shown. The steps of simulation are as follows. Firstly, High frequency return series $r_{t, i}$ are produced by GARCH process, including total 48,000 returns of 1,000 days, 48 five-minute returns each day; secondly, with these simulated series, the daily realized volatility $R V_{t}$ and the daily return series $R_{t}$ are computed; Thirdly, model the daily return series $R_{t}$ with GARCH, EGARCH, RV-GARCH, RV-EGARCH, AR, N-AR, HAR and NHAR model, and then to compute conditional volatility $\sigma_{t}^{i}$ as well as the standardized return series $\varepsilon_{t}^{k}=R_{t} / \sigma_{t}^{k}$ for each model; Repeat these steps 10,000 times to get the average value of the statistics mean, median, min, max, standard error, skew, kurtosis and J-B value for $\varepsilon_{t}^{k}$ of each model.

models with asymmetry are better to capture the volatility dynamics than the symmetric counterpart. The asymmetric models have lower kurtosis or extreme value than their symmetric ones. That is, asymmetric volatility model can capture the market high-movement event (crash) better, and the residual term has less information than that of symmetric models. So, there are evidences that better forecast ability comes from the asymmetric models themselves, but not only the case of CTBM. The asymmetric specification itself may capture more subtle volatility dynamics and lead to better forecasting.

\section{CONCLUSIONS}

This paper takes an empirical study on volatility of the Chinese Treasury bond market. The key point is the role of asymmetry in volatility modeling, including econometric testing of asymmetry property and analyzing its influence on volatility forecasting. The chief conclusions of this paper include,

1) Asymmetric relationship between return and volatility is insignificant in CTBM. This is quite different from the results in the stock or exchange market. However, asymmetry may provide important and indispensable information to volatility forecasting, which, with the results of Monte Carlo simulations, may come from the asymmetric specifications that capture more subtle volatility dynamics;

2) When comparing the forecasting ability of the popular volatility models, the asymmetric ones, RV-EGARCH $(1,1)$, N-AR $(1,5,8)$ and N-MA (1) model, behave best. In addition, with HAR models, it can be found that the medium-term investors who trade with weekly interval regularly are marginal, but short-term (daily) and long-term (monthly) investors are rather clear in CTBM. Historical realized volatility $\left(R V_{t-1}\right)$ is helpful to volatility forecasting by introducing it into the variance equation of GARCH and EARCH model.

The volatility of the capital market is complicatedly to understand. High frequency data help us to describe it better. This paper provides a comprehensive study on volatility asymmetry in the Chinese Treasury bond market, and the empirical results are interesting and different from that come from the stock or foreign exchange market. This implies that price discovering in the Treasury bond market may be different and the information-based impacts in the Chinese Treasury bond market are not as common as that in other markets. Moreover, some other hypotheses, in ad- 
dition to leverage effect or feedback effect, are expected to explain the volatility asymmetry in financial markets.

\section{Received 25 October 2007}

\section{REFERENCES}

Andersen, T. G. and Bollerslev, T. (1997). Intraday periodicity and volatility persistence in financial markets. Journal of Empirical Finance 4 115-158.

Andersen, T. G., Bollerslev, T., and Lange, S. (1999). Forecasting financial market volatility: Sample frequency vis forecast horizon. Journal of Empirical Finance 6 457-477.

Andersen, T. G., Bollerslev, T., and Diefold, F. X. et al. (2000). Exchange rate returns standardized by realized volatility are (nearly) Gaussian. Multinational Finance Journal 4 159-179.

Andersen, T. G., Bollerslev, T., and Diefold, F. X. et al. (2001). The distribution of realized exchange rate volatility. Journal of the American statistical association 3 42-55. MR1952727

Andersen, T. G., Bollerslev, T., and Diefold, F. X. et al. (2003). Modeling and forecasting realized volatility. Econometrica 3 579625. MR1958138

Baillie, R. T. and Bollerslev, T. (1989). The message in daily exchange rates: A conditional-variance tale. Journal of Business $\xi$ Economic Statistics 7 60-68. MR1951611

BAndi, F. M. and Russell, J. R. (2006). Separating microstructure noise from volatility. Journal of Financial Economics $\mathbf{7 9}$ 655-692.

Blair, B. J., Poon, S. H., and TAYlor, S. J. (2001). Forecasting S\&P 100 volatility: The incremental information content of implied volatility and high-frequency index returns. Journal of Economet rics 105(1) 5-26. MR1863145

Bollerslev, T. (1986). Generalized autoregressive conditional heteroskedasticity. Journal of Econometrics 31 307-327. MR0853051

Bollerslev, T., Chou, R. Y., and Kroner, K. F. (1992). ARCH modeling in finance-A review of the theory and empirical evidence. Journal of Econometrics 52(1-2) 5-59.

Bollerslev, T. (2000). Financial econometrics: Past developments and future challenges. Journal of Econometrics 100 51-51. MR1807787

Bollerslev, T. and Ghysels, E. (1996). Periodic autoregressive conditional heteroskedasticity. Journal of Business $\&$ Economic Statistics 14(2) 139-151.

Braun, P. A., Nelson, D. B., and Sunier, A. M. (1995). Good news, bad news, volatility, and betas. Journal of Finance 50(5) 15751603.

Corsi, F. (2003). A simple long memory model of realized volatility. Working Paper, University of Southern Switzerland.

Corsi, F., Zumbach, G., Muler, U., and Dacorogna, M. (2001). Consistent high-precision volatility from high frequency data. Economic Notes 30(2) 183-204.

Dacorogna, M., Genchy, R., and Muler, U. A. et al. (2001). An introduction to high-frequency finance. Academic press, USA.

Diamond, W. and Verrecchia, R. E. (1987). Constraints on shortselling and asset price adjustment to private information. Journal of Financial Economics 18(2) 277-311.

Ederington, L. H. and LeE, J. H. (1993). How markets process information: News releases and volatility. Journal of Finance 48 11611191.

Edwards, A., Harris, L., and Piwowar, M. (2007). Corporate bond market transaction costs and transparency. Journal of Finance 62(3) 1421-1451.
ENGLE, R. F. (1982). Autoregressive conditional heteroskedasticity with estimates of the variance of United Kingdom inflation. Econometrica 50(4) 987-1008. MR0666121

EngLE, R. (2004). Risk and volatility: Econometric models and financial practice. American Economic Review 94 405-420.

Engle, R., Lilien, D., and Robins, R. (1987). Estimating time varying risk premia in the term structure: The ARCH-M model. Econometrica 55(2) 391-407.

Forsberg, L. and Bollerslev, T. (2002). Bridging the gap between the distribution of realized (ECU) volatility and ARCH modeling (other EURO): The GARCH-NIG model. Journal of Applied Econometrics 17(5) 535-548.

Glosten, L. R., Jagannathan, R., and Runkle, D. E. (1993). On the relation between the expected value and the volaility of the nominal excess return on stocks. The Journal of Finance 48(5) 1779-1801.

Greene, W. H. (2003). Econometric Analysis (fifth edition). PrenticeHall International Inc.

HANSEn, P. R. and Lunde, A. (2005). A forecast comparison of volatility models: Does anything beat a $\operatorname{GARCH}(1,1)$ ? Journal of Applied Econometrics 20 873-889. MR2223415

Harris, L. and Piwowar, M. (2006). Secondary trading costs in the municipal bond market. Journal of Finance 61(3) 1361-1397.

Hol, E. and Koopman, S. J. (2002). Stock index volatility forecasting with high frequency data. Tingbergen Institute Discussion paper, TI2002-068/4.

Lesmond, D., Ogden, J., and Trzcinka, C. (1999). A new estimate of transaction costs. Review of Financial Studies 12(5) 1113-1141.

Martens, M. (2001). Forecasting daily exchange rate volatility using intraday returns. Journal of International Money and Finance 20(1) $1-23$

Muler, U., Dacrogna, M., and Dave, R. et al. (1997). Volatilities of different time resolutions - analyzing the dynamics of market components. Journal of Empirical Finance 4(2) 213-239.

Nelson, D. B. (1991). Conditional heteroskedasticity in asset returns: A new approach. Econometrica 59(2) 347-370. MR1097532

OMEN, R. C. (2001). Using high frequency stock market index data to calculate, model \& forecast realized volatility. Working paper, European University Institute.

Schultz, P. (2001). Corporate bond trading costs and practices: A peek behind the curtain. Journal of Finance 56(2) 677-698.

WANG, J. and YANG, M. (2006). Asymmetric volatility in the foreign exchange market. Working paper, University of New South Wales.

Zhang, L., Mykland, P., and Ait-Sahalia, Y. (2005). A tale of two time scales: Determining integrated volatility with noisy highfrequency data. Journal of the American Statistical Association 100 1394-1411. MR2236450

ZAKOIAN, J. M. (1994). Threshold heteroskedastic model. Journal of Economic Dynamics and Control 18 931-955.

\section{Dijun Tan}

School of Management and Economics of UESTC

Chengdu, 610054 China

E-mail address: tandj516@uestc.edu.cn

\section{Yixiang Tian}

School of Management and Economics of UESTC

Chengdu, 610054 China

E-mail address: tianyx@uestc.edu.cn 